\title{
Contamination profiles of antifouling biocides in selected coastal regions of Malaysia
}

\begin{abstract}
The concentrations of butyltins (BTs) in sediment from Peninsular Malaysia along the Strait of Malacca and their spatial distribution are discussed. The concentrations of BTs were high in the southern part of Peninsular Malaysia where there is a lot of ship traffic, because trade is prosperous. The concentrations of monobutyltin (MBT), dibutyltin (DBT), and tributyltin (TBT) in sediment from the coastal waters of Peninsular Malaysia were in the range 4.1-242 microg/kg dry weight (dw), 1.1-186 microg/kg dw, and 0.7-228 microg/kg dw, respectively. A higher percentage of TBT was observed in the area where TBT concentrations were high. The concentrations of monophenyltin (MPT), diphenyltin (DPT), and triphenyltin (TPT) were in the range <0.1-121 microg/kg dw, 0.4-27 microg/kg dw, and 0.1-34 microg/kg dw in sediment from Peninsular Malaysia, respectively. MPT was the dominant phenyltin species. MBT, DBT, and TBT in green mussel (Perna viridis) samples were detected in the range 41$102 \mathrm{microg} / \mathrm{kg}, 3-5 \mathrm{microg} / \mathrm{kg}$, and 8-32 microg/kg, respectively. A tolerable average residue level (TARL) was estimated at $20.4 \mathrm{microg} / \mathrm{kg}$ from a tolerable daily intake (TDI) of 0.25 microg TBTO/kg body weight/day. The maximum value of TBT detected in green mussel samples was the value near the TARL. TPTs were not detected in green mussel samples. The concentrations of Diuron and Irgarol 1051 in sediment from Peninsular Malaysia were in the range $<0.1-5 \mathrm{microg} / \mathrm{kg} \mathrm{dw}$ and $<0.1-14 \mathrm{microg} / \mathrm{kg} \mathrm{dw}$, respectively. High concentrations of these compounds were observed in locations where the concentrations of TBT were high. Sea Nine 211, Dichlofluanid, and Pyrithiones were not detected in sediment. The concentrations of antifouling biocides in Melaka and the Strait of Johor were investigated in detail. BTs were found in similar concentrations among all sampling sites from Melaka, indicating that BT contamination spread off the coast. However, Sea Nine 211, Diuron, and Irgarol 1051 in the sediment from Melaka were high at the mouth of the river. BT concentrations at the Strait of Johor were higher than those in Peninsular Malaysia and Melaka and were high at the narrowest locations with poor flushing of water. The concentrations of antifouling biocides were compared among Malaysia, Thailand, and Vietnam. A higher concentration and wide variations of TBT and TPT in sediment from Malaysia were observed among these countries. The Irgarol 1051 concentrations in sediment from Malaysia were higher than those in Thailand and Vietnam.
\end{abstract}

Keyword: Antifouling biocides; Butyltins; Sediment; Peninsular Malaysia; Strait of Malacca; Malaysia 